\title{
La batalla de los manuales en Colombia ${ }^{\mathrm{A}}$
}

\section{Germán Colmenares}

El saber histórico se muestra hoy mucho más modesto, o más escéptico, que en épocas pasadas, sobre su presunta utilidad. Creo que muy pocos historiadores dentro de la comunidad académica internacional pondrían en duda las conclusiones del historiador inglés J. H. Plumb sobre "la muerte del pasado". Según Plumb, la historia debe ayudarnos a exorcizar el pasado, o al menos un pasado que ha sido creado como una ideología que busca "controlar individuos, o motivar sociedades o inspirar clases". La historia solo puede alcanzar sus virtualidades como conocimiento en la medida en que ayuda a limpiar la corrupción de "engañosas visiones de un pasado con finalidad". Pero si el historiador ya no puede, en palabras de Plumb, "proporcionar legitimaciones a la autoridad, ni a las élites oligárquicas o aristocráticas, ni a destinos inherentes cobijados bajo un ropaje nacional", en cambio sí puede enseñar algo todavía con respecto a la naturaleza del cambio social ${ }^{1}$.

Aquí cabe preguntarse cuál puede ser el destino de esta pequeña parcela de sabiduría que les queda a los historiadores en países en los que el cambio social encuentra las resistencias más enconadas y en los que, en medio de las más extremadas convulsiones sociales, los esfuerzos por comprender el cambio se señalan como una complicidad con fuerzas oscuras y desestabilizadoras. Un buen ejemplo, entre otros

A En Michael Riekenberg, comp., Latinoamérica: la enseñanza de la historia, libros de texto y conciencia histórica [edición alemana de 1990] (Buenos Aires-Madrid: Alianza Editorial, FLACSO, George Eckert Instituts, 1991), 122-134. El texto de Colmenares explica de manera clara la breve historia de una polémica que, como dijo Jorge Orlando Melo, en punto recordado por Colmenares, era a todas luces una polémica mal planteada. Queda aún la tarea de volver a leer los textos de la "nueva historia" que estuvieron en el centro de la polémica sobre los manuales escolares, para observar sus virtudes y defectos, más allá de la coyuntura que produjo la discusión que aquí se recrea. En mi opinión la mayor parte de esos libros no eran, de manera explicable, grandes creaciones, reproducían muchas de las limitaciones que se encontraban ya en la "historia económica a la colombiana", limitaciones que algunos de ellos llevaban aún más lejos y, tal vez con una sola excepción, no escapaban al populismo histórico que por años ha rondado la práctica de los historiadores que se han definido como "historiadores de los sectores populares" o de convicción socialista y democrática. Nunca se ha emprendido la lectura juiciosa de tales textos pensados como de divulgación - algunos fueron a su manera éxitos de ventas, lo que dice mucho sobre la aspiración a otra historia entre maestros y estudiantes de secundaria-. Me imagino que la ausencia de esa tarea de lectura y de investigación tiene que ver tanto con los cambios constantes de las modas historiográficas, lo que nos somete a la lógica del abandono constante de temas que aún no empiezan a estudiarse con juicio, pero también con el hecho de que el buen sentido de "académicos y estudiantes de izquierda" nos conduce al juicio simplista de que si fueron criticados y atacados por la academia de Historia deben ser muy buenos.

1 J. H. Plumb, The Death of the past (Boston: Houghton Mifflin Company, 1971). 
países de América Latina, podría ser el de Colombia. En el curso del último medio siglo Colombia ha traspasado definitivamente los umbrales de lo que podía designarse vagamente una sociedad tradicional y ha penetrado en las incertidumbres de las sociedades modernas. Esta transformación radical ha estado repleta de incoherencias y se ha acompañado de violencias inauditas. Durante casi dos decenios, un crecimiento demográfico sin precedentes, que anula los efectos de cualquier meta razonable de desarrollo, coexistió con un vasto movimiento de migraciones rurales que invirtieron los patrones de asentamiento de la sociedad colombiana. Tres cuartas partes de un país que apenas impresionaban la retina de los viajeros con imágenes bucólicas de sociedades campesinas vinieron a agolparse de súbito en barriadas urbanas en demandas de las más elementales condiciones de vida.

Fenómenos de esta amplitud debían someter a una prueba muy ruda no solo a las instituciones establecidas o a la capacidad de respuesta de los grupos dirigentes, sino también a los patrones mentales mismos con los cuales se enfrentaba el cambio social. Este mismo desafío debía encararse por parte de las disciplinas académicas. Algunas de ellas, como la economía y la sociología, interrogaban inútilmente a los historiadores en búsqueda de respuestas a algunos problemas como la evolución de los patrones de tenencia de la tierra, las formas históricas de la evolución del trabajo, los ciclos demográficos, la expansión de fronteras agrícolas, los factores históricos de procesos de industrialización, el origen de tensiones regionales, las características de la formación de empresarios, la base étnica original de conformación de sectores sociales, el sentido de la formación cultural, el significado exacto y el papel histórico de caudillos y gamonales: la lista de problemas que debían abordarse con urgencia podría ser interminable. Sin embargo, la naturaleza del saber histórico, tal como se concebía en Colombia hacía 1950, inhibía cualquier respuesta seria y fundamentada a estos problemas. Veamos brevemente por qué.

\section{II}

Tradicionalmente, el Ministerio de Educación, con la asesoría de la Academia Colombiana de Historia, ha ejercido un control sobre la enseñanza de la historia en los niveles medio y elemental. Los textos escolares reflejan, así sea con algún retraso y de manera simplificada, el estado de las investigaciones y del saber histórico. Que estos últimos no hayan sido muy dinámicos durante toda la primera mitad de este siglo $[\mathrm{XX}]$, parece demostrado por el hecho de que el texto canónico por excelencia destinado a la enseñanza de la historia patria y algunos derivados, se hayan mantenido inalterados hasta hoy. El texto de los señores académicos José María Henao y Gerardo Arrubla, una síntesis muy útil para apreciar los problemas que planteaba la historiografía colombiana del siglo XIX, se convirtió en el texto escolar por exce- 
lencia ${ }^{2}$. Este texto ganó un concurso abierto en 1910 para celebrar el centenario de la independencia y fue adoptado mediante un decreto de gobierno como texto oficial para la enseñanza secundaria. Un compendio de la misma obra se destinó como guía de la enseñanza primaria.

Las circunstancias que rodearon la producción de este manual ayudan a comprender los objetivos que se fijaba. El siglo XIX se había cerrado con una de las guerras más sangrientas del periodo. Con esta guerra, la confrontación de los partidos tradicionales parecía haber llegado a un ápice que ponía en tela de juicio la conformación misma de un Estado nacional. Los elementos objetivos de esta conformación estaban dados por la consolidación de un modelo agroexportador que orientaba tanto la gestión económica como la unificación de un mercado interno y por la institucionalización de un sistema centralista para el Estado, que ambos partidos habían terminado por aceptar. Las cuestiones doctrinarias que habían dividido la opinión en el curso del siglo XIX no parecían entonces tan urgentes como la tarea de emprender obras de progreso y de dotar al Estado de los medios que las hicieran posibles. Por eso se imponía liquidar un estilo de gobierno intolerante y excluyente. La concordia y la reconciliación parecían tanto más urgentes cuanto que, en medio de las disensiones partidistas, el país había perdido una parte sustancial de su territorio. La fundación de la Academia Colombiana de Historia en 1902 estuvo inspirada por este espíritu de reconciliación que quería uncir el pasado a una visión promisoria y optimista del progreso. El manual de los dos académicos expresaba con meridiana claridad la intención de superar toda afirmación doctrinaria para resaltar del pasado todo aquello que fuera digno de imitación y de encomio. En él se equilibraba cuidadosamente la visión conservadora del siglo XIX, que ponía énfasis en la empresa de cristianización y en la misión civilizadora europea de los periodos de la conquista y de la colonia, con la insistencia liberal en el periodo de la independencia como paradigma de un proceso en el que se buscaba afirmar la necesidad del imperio de la ley sobre las pasiones o las imposiciones autoritarias de los caudillos ${ }^{3}$. La conciliación de estas dos nociones interpretativas debía convertir una secuencia de eventos políticos y de batallas en una materia sagrada que debía asimilarse ritualmente.

Las necesidades de una religión patriótica debían limitar forzosamente el rango de las preguntas sobre el pasado y acumular simplemente materiales reiterativos sobre las mismas cuestiones. A lo sumo, una tendencia conservadora podía expresarse por la preferencia a subrayar la importancia del periodo colonial y la acción de la Iglesia y

2 Jesús María Henao y Gerardo Arrubla, Historia de Colombia, séptima edición (Bogotá: 1952). La última edición de la obra, realizada por la Academia Colombiana de Historia, data de 1984.

3 Los autores más representativos de estas tendencias fueron José Manuel Restrepo, Historia de la revolución en Colombia, 6 vols. (Medellín: 1969). La primera edición realizada en París data de 1827, la segunda edición aumentada de 1858, y José Manuel Groot, Historia eclesiástica y civil de la Nueva Granada, 5 vols. (Bogotá: 1953); la edición original data de 1869. 
una tendencia liberal a enfatizar más bien los desarrollos republicanos y el culto abstracto de la ley. Pero ninguna investigación podía alterar el contenido esencial de una historia a la que le habían limado las aristas. La enseñanza de la historia debía sujetarse a este arreglo sin correr el riesgo de volver a incurrir en controversias doctrinarias en las aulas escolares. Por esta razón un académico de la historia sostenía la necesidad de separar la investigación histórica de la enseñanza. La enseñanza requería, según su punto de vista, una manipulación de hechos para lograr su "conciliación" y una manipulación de la conciencia estudiantil para imprimir en ella "lo vivo de una imagen, la ejemplaridad de un acto"4.

Varias generaciones de colombianos no tuvieron otro horizonte histórico que la narrativa lineal del texto de los señores Henao y Arrubla, en la que los gobernantes se sucedían unos a otros como un emblema de legitimidad en la sucesión del poder. Esta síntesis episódica resultaba, sin embargo, demasiado extensa, por lo cual algunas comunidades religiosas, que tenían una parte considerable en la educación privada, hicieron adaptaciones del texto canónico. El texto de mi propio bachillerato ${ }^{5}$, que en 1960 alcanzaba la 9a "edición revisada" (la revisión consistía en añadir los nombres de la Junta Militar y de Alberto Lleras que habían accedido al poder desde la sexta edición de 1954), invitaba a un "acercamiento a los umbrales de la historia" para "acendrar el más noble sentimiento de la nacionalidad". Con este objetivo en mente, el autor dedicaba 218 páginas de 420 a narrar las gestas de la independencia. El carácter religioso que se impartía a este "umbral" diluía una temporalidad antes y después de las gestas históricas. Los veinte años de ocurrencias entre 1810-1830 pugnaban por llenar casi todo el texto, la intensidad de la "historia-batalla" invadía casi íntegra la temporalidad de papel y se cerraba en sí misma como sentido del resto de la historia. Este esquema estaba calcado de la concepción histórico-religiosa agustiniana en la que la Encarnación trasciende su propia temporalidad para dotar de sentido a la historia humana entera. Unas cuantas páginas, ordenadas por sucesión de gobernantes republicanos, apuntaban aquí y allá a un proceso puramente secular, en el que debían registrarse los progresos materiales, las guerras civiles, las controversias entre los partidos, pero no como desenlace de la parte sagrada, sino más bien como su negación, o como un contraste que debía servir para idealizar todavía más el núcleo esencial e intocable de la historia patria.

La historia republicana, concebida exclusivamente como encadenamiento de sucesos políticos, tenía algunos riesgos. Las acres recriminaciones mutuas entre los partidos debido a una violencia política que parecía incontrolable entre 1950-1970, contribuían a realzar todavía más la identificación del periodo 1810-1830 como el pa-

4 Jorge Cárdenas García, Crítica y polémica (Tunja: Ediciones la rana y el águila, 1972). Citado por Bernardo Tovar Zambrano, La colonia en la historiografía colombiana (Bogotá: 1974), 124.

5 Hermano Justo Ramón, Historia de Colombia. Significado de la obra colonial, Independencia y República, 9ª edición (Bogotá: Ediciones LAVP, 1960). 
radigma de la historia patria. Según un manual concebido en un espíritu de tolerancia en 1942 y todavía en uso treinta años después ${ }^{6}$, el tratamiento de la época republicana, y aun el de la independencia, se prestaba a menudo a interpretaciones partidistas. Algunos maestros evitaban tocar el periodo republicano que, centrado en una historia política en la que se alternaban presidentes liberales y conservadores, podía "relacionarse íntimamente con los intereses y pasiones de los partidos". De esta manera, se convertía "en manantial de la discordia lo que debe ser motivo de comprensión y fuente de armonía para todos los colombianos".

Algunas cuestiones mal planteadas daban lugar a las más extrañas apologías o a las condenaciones morales más grotescas. Como una introducción sumaria a la historia patria, los autores de manuales escolares se sentían obligados a hacer un balance preliminar sobre el significado de la conquista española y del periodo colonial. En veinte o treinta páginas se despachaban 300 años, una vez que se decidía sobre la "cuestión española" y sobre la "cuestión indígena".

La "cuestión española" debía responder a una pregunta retórica sobre si la conquista había traído beneficios a los primitivos habitantes de América. La respuesta a este curioso problema debía balancearse cuidadosamente por cuanto treinta páginas más adelante los estudiantes encontrarían la exposición de las querellas de los próceres contra el coloniaje español. Veamos uno de estos juicios, tomado de un manual que en 1972 había merecido una duodécima edición:

Consecuencias de la conquista española: si somos imparciales y justos , tenemos que alabarla por los grandes beneficios que nos reportó: de España recibimos el beneficio incalculable de la religión que mostró a nuestros indígenas el sendero del mundo mejor que esperamos y señaló también a aquellos el camino de la virtud y los purificó de los vicios; España nos dio su sangre que, en fusión con la indígena, dio como resultante una raza privilegiada; nos dio su idioma, rico y encantador ${ }^{7}$.

La "cuestión indígena" no exigía de este autor tantos esfuerzos a su imaginación valorativa: "La cultura azteca como la [maya] — nos enseñaba- es esencialmente digna de encomio", y acto seguido enumeraba aquellos rasgos que merecían su aprobación. Para agregar enseguida: "Todo esto, no obstante, la moral mejicana era muy inferior a la de las naciones auténticamente civilizadas... el pueblo mejicano presenta fuertes contrastes de grandeza y abyección; aunque no fuera sino por su canibalismo, este pueblo debía perecer". Después de enumerar algunas de las culturas americanas con juicios de valor siempre rotundos, el manual dedicaba unos cuantos párrafos a "las culturas inferiores" y nos enseñaba que, "hecha salvedad de los pueblos anteriormente

$6 \quad$ Julio César García, Historia de Colombia (Medellín: 1942).

7 Rafael María Granados, Historia de Colombia. La Independencia. La República, $12^{\mathrm{a}}$ edición (Bogotá: 1972), 14 
mencionados, las demás naciones americanas son dignas de compasión profunda por su abyección y envilecimiento".

Estos juicios sin apelación, en un país que todavía cuenta con grupos indígenas que se ven cada vez más amenazados por la explotación y la injusticia, no eran muy tonificantes. Como no lo eran los calificativos a quienes participaban en movimientos populares a mediados del siglo XIX de "elementos abyectos de la sociedad" o "chusmas secuaces".

\section{III}

La carencia más obvia de los manuales dedicados a la enseñanza de la historia patria ha sido sin duda su falta de apoyo en la investigación histórica. Las gestas patrióticas pueden reproducirse en detalle gracias a la labor de los historiadores del siglo XIX que dieron a su presentación una forma canónica. Con ellas quiere transmitirse el sentimiento exaltado de los próceres mismos, que inventaron un lenguaje con el cual podía sustituirse la majestad monárquica y sus atributos de justicia y de clemencia. La legitimación a través de símbolos enfermizos como el de la "sangre derramada" pronto se encarnó en la figura misma del héroe. Este aspecto religioso-ritual de la revolución iba a ser el elemento más duradero de las historias patrias. El mismo núcleo básico ha podido enmarcarse en patrones de historia institucional y adicionarle algunas consideraciones culturales (sobre todo el arte en la Colonia por ejemplo) o detalles superficiales sobre la economía o las distinciones basadas en las etnias.

Desde mediados de los años cincuenta y comienzos de los sesenta aparecieron obras aisladas en las que un problema concreto recibía un análisis riguroso y un tratamiento metodológico adecuado. Estas obras fueron precedidas por la aparición en 1942 del libro de Luis Eduardo Nieto Arteta sobre Economía y cultura en la historia de Colombia, el cual desplazaba el centro de gravedad de la historia colombiana de la época heroica al periodo de las llamadas reformas del medio siglo. Al concentrar su atención sobre este periodo, Nieto Arteta podía establecer con más claridad las conexiones entre las transformaciones de la economía y la posición de los diversos actores sociales que comenzaban a expresarse a través de los partidos políticos ${ }^{8}$. En 1955 apareció una obra pionera ${ }^{9}$ que volvía a insistir en la complejidad de las relaciones entre el desarrollo económico y la política al exponer detalladamente los vaivenes de la política económica entre 1810-1830. Debe decirse, sin embargo, que la obra de Don Luis Ospina Vásquez tuvo un efecto inmediato más perceptible en las investigaciones de estudiantes anglosajones que en las de los colombianos. En 1957 apareció un libro

8 Luis Eduardo Nieto Arteta, Economía y cultura en la historia de Colombia, 2a edición (Bogotá: 1962).

9 Luis Ospina Vásquez, Industria y protección en Colombia (Bogotá: 1955). 
de un sociólogo, Orlando Fals Borda ${ }^{10}$, que ponía en primer plano a un indio que el trajín de los fastos heroicos había hecho desaparecer misteriosamente. Por su parte, un etnohistoriador, Juan Friede ${ }^{11}$, venía insistiendo tercamente también en la realidad histórica tangible del indio en Colombia, y un antropólogo, Gerardo Reichel-Dolmatoff, sintetizaba en $1962^{12}$ el significado de sus propios hallazgos y el de otros trabajos arqueológicos de por lo menos dos décadas. En 1963 apareció el primer [número del] Anuario de historia social y de la cultura de la Universidad Nacional de Colombia bajo la dirección de Jaime Jaramillo Uribe. A partir de entonces, la investigación histórica fue afianzándose en las universidades colombianas en donde se crearon programas para formar docentes e historiadores profesionales ${ }^{13}$.

En el último cuarto de siglo, la institucionalización de la investigación en las universidades públicas y en algunas de las privadas ha multiplicado las perspectivas históricas ${ }^{14}$. Se conoce mejor la historia de la tenencia de la tierra, ha habido investigaciones y debates sobre el modelo agroexportador del siglo XIX y los ciclos de la agricultura comercial, existen exploraciones sobre demografía histórica, el análisis de los partidos políticos ha perdido el esquematismo doctrinario y las guerras civiles del siglo XIX se ven en una perspectiva económica y social, se discierne mejor la función de las categorías sociales en cada periodo histórico, la historia de la educación, de la ciencia y del arte están en pleno florecimiento e inclusive el análisis de la violencia reciente se ha convertido en un punto de confluencia interdisciplinaria para historiadores, sociólogos y científicos políticos. Sin alcanzar las proporciones de una industria académica, toda esta producción ha encontrado canales de difusión a través de revistas y de colecciones universitarias y hasta de grandes proyectos editoriales ${ }^{15}$. A partir de 1974 se celebra cada dos años un congreso nacional de historiadores, del cual ha surgido una asociación en 1987. La normalización del trabajo investigativo ha permitido también la recepción y difusión de trabajos de especialistas norteamericanos y europeos que solían permanecer ignorados, aunque tocaran problemas esenciales del país.

10 Orlando Fals Borda, El hombre y la tierra en Boyacá (Bogotá: 1957).

11 Juan Friede, El indio en la lucha por la tierra (Bogotá: 1944); Juan Friede, Los Andaki (1538-1947). Historia de la aculturación de una tribu selvática (México: 1953); Juan Friede, Vida y luchas de Don Juan del Valle, primer Obispo de Popayán y protector de indios (Popayán: 1961).

12 Gerardo Reichel-Dolmatoff, Colombia, Ancient Peoples and Places (Londres: 1965).

13 Actualmente existen programas de maestría en Historia en las universidades Nacional (Bogotá y Medellín), del Valle, Tunja y Externado de Colombia. Casi todas las universidades tienen un departamento de Historia, muchas con programas de pregrado.

14 Jorge Orlando Melo ha elaborado periódicamente evaluaciones del trabajo historiográfico en Colombia. Véase, por ejemplo, "Los estudios históricos en Colombia: situación actual y tendencias predominantes" (1969) en Sobre historia y política (Bogotá: 1979); "La literatura histórica en la última década", en Boletín Cultural y Bibliográfico, 25.15 (1988) y una visión más general de la historiografía colombiana en "La literatura histórica en la República", en Manual de literatura colombiana, t. II (Bogotá: 1988).

15 El más reciente, bajo la dirección de Álvaro Tirado mejía (Nueva Historia de Colombia, 9 vols. Bogotá: 1989), reúne trabajos de 66 especialistas. También la Historia de Antioquia (Bogotá: 1988), un proyecto de historia regional bajo la dirección de J. O. Melo, reúne los trabajos de 42 especialistas. 
Esta actividad investigativa ha captado también influencias muy diversas en lo que respecta al método o a las teorías sociales. Usualmente se señala la influencia obvia de [la Escuela de los] Annales y del rigor empírico de los trabajos universitarios anglosajones. Pero también ha habido un debate muy vivo con diversas tendencias marxistas, sobre todo en el curso del decenio pasado. Hoy comienza a haber un acercamiento a desafíos y problemas que plantean otras disciplinas. En Colombia se ha producido el caso único de que muchas innovaciones historiográficas provengan de economistas y, todavía más raro, de que los economistas mantengan un debate con los historiadores.

\section{IV}

Todo esto comienza a reflejarse en los manuales dedicados a la enseñanza media y elemental. Desde hace poco más de diez años han ido ganando terreno los manuales producidos en medios universitarios. Uno de los más difundidos ${ }^{16}$, aunque forzosamente elíptico y metido dentro de la camisa de fuerza de los programas oficiales, significa al menos un compromiso entre la narrativa tradicional y los resultados de investigaciones recientes. Intentos más radicales de romper con patrones cronológicos y de introducir en las aulas escolares una discusión viva no apoyada en la autoridad de los textos, ha suscitado la alarma de la Academia Colombiana de la Historia.

La publicación, a finales de 1984, de dos manuales dedicados a estudiantes de cuarto año de primaria, desató una viva polémica ${ }^{17}$. El autor de uno de estos manuales había coordinado el año anterior un grupo de consulta de la Unesco sobre "la enseñanza de la historia en los países del área andina”. El análisis de algunos textos escolares en uso en cuatro de estos países revelaba no solo la pobreza de las concepciones históricas que pretendían transmitirse, sino fallas pedagógicas protuberantes. Las conclusiones de la consulta señalaban un tratamiento sesgado de los actores históricos que se limitaban a grandes personajes políticos y militares. La exaltación de figuras ejemplares inimitables por los privilegios de su origen social imponía secuencias narrativas de hechos exclusivamente políticos y militares, lo que a su vez conducía a una excesiva parcelación de eventos en los que era imposible reconocer una estructura. El resultado pedagógico era la imposición dogmática de una materia en la que debían memorizarse secuencias de datos a los que se atribuía una significación propia, o que debían hablar por sí solos.

16 Carlos Alberto Mora y Margarita Peña, Historia socioeconómica de Colombia (Bogotá: 1985). En la misma línea, aunque con menos difusión, Manuel Lucena S. y Consuelo Gaviria de Vesga, Historia de Colombia (Bogotá: 1981).

17 Fernando Torres Londoño y Rodolfo Ramón de Roux, Nuestra historia 4 y 5 (Bogotá: 1985). También de De Roux véase "Historia y Educación", en Educación y Cultura. Revista de Fecode, diciembre de 1987. 
A través de esta crítica pedagógica pueden reconocerse los resultados de una narrativa sujeta a los esquemas del positivismo del siglo XIX. Por eso los nuevos manuales buscaban introducir innovaciones pedagógicas y de contenido. Con una presentación atractiva, a veces humorística, los manuales incitaban a una discusión en las aulas de problemas tales como la participación popular en los eventos políticos, el desarrollo de movimientos colonizadores en el siglo XIX, el contenido social de las guerras civiles, la rigidez y la persistencia de las estructuras sociales.

La respuesta de la Academia de Historia no se hizo esperar. El presidente de esta institución, vinculado como columnista y editorialista del periódico de mayor difusión en el país, escribió una nota con el título "Historia a patadas"18. En su nota, el doctor Germán Arciniegas citaba algunos párrafos del manual con una sugerencia velada de que se trataba de una "demolición de la historia en beneficio de los que sabemos". Se quejaba particularmente de que el manual no mencionara a cuatro de los héroes de la Independencia y al fundador del periódico en el que aparecía su nota, presidente de la república en los años de la Segunda Guerra Mundial. Un mes más tarde, el presidente de la Academia acusaba más explícitamente al manual de incitar al comunismo y de ridiculizar los logros de la vida republicana y democrática ${ }^{19}$. Otro académico, más radical, sostenía que estos manuales "dejan muy mal a España y a sus hijos más directos, los criollos, en favor de mulatos e indios... se inculca odio a los próceres, a los españoles, a los criollos y se exalta la fuerza aun por explotar (el imperio por venir) de los indios, negros y mulatos" ${ }^{20}$.

La posición de los académicos, apoyada por editoriales del periódico, fue controvertida por otros columnistas y por historiadores universitarios. Así, durante tres años los manuales se siguieron utilizando con la condena moral de la Academia, pero sin acciones administrativas en su contra. La aparición de un tercer manual, destinado al bachillerato y obra de un economista y profesor emérito de la Universidad Nacional, volvió a desatar las condenaciones de la Academia y la incitó a pedir oficialmente la censura del libro por parte del Ministerio de Educación Nacional. Sobre esta nueva polémica, un respetado historiador colombiano concluye ${ }^{21}$ : "Probablemente tras esta actitud de condena a libros que muestran la historia nacional en toda su complejidad, que incluyen dentro de sus temas el desarrollo de la economía, la narración de los conflictos sociales, las transformaciones en la vida de los colombianos, y que dan menos importancia a los próceres, existe una visión paternalista que no cree ni respeta la inteligencia de los colombianos, y que cree que a estos les sirve y se les educa mejor engañándolos y ocultándoles aspectos de la realidad".

18 El Tiempo, 31 de octubre de 1985. Los materiales periodísticos de esta polémica fueron reproducidos con el título “¿Nuestra historia? A propósito de una polémica” (Bogotá: 1989).

19 "La gallina Nicaragua", El Tiempo, 14 de noviembre de 1985.

20 "Textos de historia colombiana provocan batalla académica", El Colombiano, 7 de marzo de 1989.

21 J. O. Melo, "Polémica mal planteada" en Lecturas dominicales de El Tiempo, 9 de abril de 1989. 
Un historiador debería sentirse halagado por el hecho de que su disciplina se convierta, de pronto, en el centro de un debate nacional. En muchos aspectos, de manera extrañamente anacrónica, el debate recuerda la controversia de finales del periodo colonial, cuando don José Celestino Mutis quiso introducir en la enseñanza el sistema copernicano contra la obstinada defensa del viejo sistema tolemaico por parte de una orden religiosa encargada de velar por la sana doctrina. Sin embrago, resulta lamentable, que este debate no se oriente hacia la discusión de problemas pedagógicos en una sociedad en la que los cambios sociales transcurren por cauces imprevisibles. 